10 years ESJ

Special edition

\title{
Mechanisms to Encourage Vaccination of Public and State-Funded Employees in the Autonomous Republic of Adjara
}

\author{
Mariam Davitadze \\ Grigol Robakidze University, Batumi, Georgia
}

Doi:10.19044/esj.2022.v18n5p40

Submitted: 11 November 2021

Accepted: 24 January 2022

Published: 21 February 2022
Copyright 2022 Author(s)

Under Creative Commons BY-NC-ND

4.0 OPEN ACCESS

Cite As:

Davitadze M. (2022). Mechanisms to Encourage Vaccination of Public and State-Funded Employees in the Autonomous Republic of Adjara. European Scientific Journal, ESJ, 18 (5), 40. https://doi.org/10.19044/esj.2022.v18n5p40

\begin{abstract}
The present article is dedicated to the discussion of such a topical issue as the mechanisms for encouraging vaccination of public and state-funded employees in the Autonomous Republic of Adjara. The paper is an observational analysis as it discusses the ongoing process of vaccination as one of the main means of combating the pandemic in Georgia and other topical issues related to it. Based on the observation of the situation in the public sector of Adjara Autonomous Republic, the advantages and disadvantages of vaccination are assessed, the risks are presented and recommendations are made for voluntary involvement of more citizens in the vaccination process. In particular, the forms of vaccination incentives for state-funded and public employees who will significantly contribute to the rapid and positive impact of vaccination are evaluated.
\end{abstract}

Keywords: COVID-19, vaccination, campaign, incentives, public sector employees, Adjara Autonomous Republic

\section{Introduction}

In the context of the current pandemic, the World Health Organization has authorized several vaccines, which it considers the only means of eradicating and spreading the Covid-19 pandemic. 
Leading countries in the world, including the United States, China, and EU member states, were immediately involved in the vaccination process, which allowed them to gradually start rebuilding their economies and lifting restrictions. Which is directly related to the improvement of the economic situation of these states, sustainable development and ensuring the social status of the citizens. Working on the article, the experience of government agencies, the World Health Organization, NGOs and various countries was analysed. According to the results, the vaccination process in Georgia is relatively low, which is due to the lack of confidence of citizens in the vaccine against the covid pandemic, which is caused by scarce information about the vaccine, the side effects of the vaccine, excessive negative information about the vaccine, voluntary vaccination and weak communication from the state about vaccination. Defeating the pandemic caused by Covid 19 is possible by vaccinating at least $60 \%$ of the total population, and distrust of vaccination by citizens is a particular problem for the state in terms of enforcing the vaccination process. The theoretical-methodological basis of the article is the study of the existing international standards, regulations or mechanisms for the protection of ethics at the national level, as well as the study of various works and the relevant conclusion based on the analysis of information collected on the problem. The urgency of the problem in Georgia is emphasized, in particular, by the increase in the number of people infected in the Autonomous Republic of Adjara and in anti-vaxxers in the region (Antiadvertising, negative PR campaigns about vaccinations produced by antivaxxers should be blocked by Facebook and there should be punitive measures when disseminating such information). A large group of anti-vaxxers negatively affects the effectiveness of the vaccination process. Due to the existing practice, the vaccination process was delayed in Georgia due to the attempts of anti-vaxxers, when the vaccines were booked by a large group of anti-vaxxers and subsequently cancelled in order to prevent vaccination by the citizens.

As a result of the Covid-19 pandemic, the modern world is still facing an insurmountable challenge. According to the latest data from the Johns Hopkins University Center for Science and Advanced Technology Research (Science and Modern Technology Research Center at Johns Hopkins University, 2020) on the first case of the spread of coronavirus, more than 207 million people were infected on Earth, and the death toll has increased and exceeds 4 million people. The World Health Organization considers the Covid pandemic to be a problem of the current century and daily offers the world recommendations on how to effectively combat the virus and prevent its spread. In early 2021 , by the same organization was accredited a group of Covid vaccines, which are actively used in different countries of the world. In addition, the World Health Organization calls on governments to ensure that 
vaccines are procured on time and quickly delivered to the public (World Health Organization, 2021). Despite the active campaigns of the world's leading countries and the organization of various events, there is still some distrust of the vaccine and a large part of the population is skeptical about the positive effects of the vaccine, often citizens refuse to be vaccinated, and they justify this by various factors. At the same time, the so-called Groups of antivaccines, which negatively inform citizens about the different content of the vaccine, urge them not to get involved in the vaccination process. The influence of these groups is quite large and a certain part of the population is their fans. However, the modern scientific community, the World Health Organization, and other reputable international organizations are still conducting research on vaccines around the world, and their scientific evaluations have once again confirmed their safety and efficacy.

\section{Forms of vaccination incentives abroad and in Georgia}

The Covid-19 virus was first detected in Georgia in February 2020, and since then, according to the official information of the online platform created by the Georgian government, more than 480 thousand infected people, including more than 425 thousand have recovered, unfortunately, more than 6 thousand people have died. The Government of Georgia has established an Interagency Coordinating Council for Combating and Preventing the Virus, which has developed various types of recommendations with the National Center for Disease Control, as well as imposed restrictions (Government of Georgia. Prevention of Coronavirus Spread in Georgia, 2020). It is a fact that at the first stage of the spread of the virus, as a result of strict quarantine and restrictive measures, no critical limit for the spread of the virus was observed in Georgia.

The process of voluntary vaccination in Georgia started in April 2021. Initially, the registration of risk groups began, including the registration of military personnel, medical personnel, as well as citizens by age. In the beginning, the activity of citizens was quite high. In the first week of vaccination in the country, a citizen died after the vaccination procedure. This fact was investigated by the relevant authority and it was established that the death of the citizen was caused not by the vaccine but by the delay in receiving medical care (Civil.ge. 2021). This fact had a negative impact on the mood of citizens regarding the safe conduct of the vaccination process. Citizens of Georgia have the opportunity to choose not one specific vaccine, but several vaccines. The Government of Georgia has developed a recommendation campaign, which calls on citizens to be involved in the vaccination process, to comply with the established regulations, thus preventing the spread of the virus. 
It should be noted, however, that the government recommendation campaign fails to ensure the effectiveness of the vaccination process, and even those public employees and most of state-funded employees refuse to be vaccinated using various arguments. Most public employees are afraid to get vaccinated because they do not have enough information and expect negative results after vaccination. Due to these circumstances, it becomes necessary to adopt regulations that indirectly or directly oblige the population to be vaccinated.

In Germany, there are different opinions about the introduction of compulsory vaccination. There is an opinion that compulsory vaccination of public employees is necessary, but there are arguments against compulsory vaccination. The advantage of compulsory vaccination of public employees is explained by the fact that it significantly contributes to public welfare in various fields. The German government plans to develop various mechanisms to ensure a broader vaccination process for the general public, including officials and those who use government services. Because in the current situation the majority of the society does not produce the desired result in the form of voluntary vaccination.

There are three main forms of vaccination incentives in Germany: 1) vaccine reduces mortality; 2) prevents the introduction of restrictions due to the spread of the disease; 3 ) altruistic forms, which include influencing selfawareness of people, the purpose of which is to induce the population to get vaccinated in order to protect people for whom vaccination is impossible (Deutsches Ärzteblatt International, 2020).

According to the data published on the website of the Government of Georgia, the total number of vaccinated people for the current period is 806 681 citizens, the number of daily vaccinations does not exceed 26000 , which indicates a rather low activity (Government of Georgia, 2021). According to the forecast of the National Center for Disease Control of Georgia, in order for up to $60 \%$ of Georgian citizens to be vaccinated by the end of this year, the daily rate should be equal to 35,000 administered vaccines; this frequency has not been reached for now (NCDC.Ge, 2021).

The number of infected citizens is increasing daily; the infection rate is equal to $10.4 \%$, which is quite high. According to the Johns Hopkins Research Center, Georgia ranks first in terms of mortality per million inhabitants (Science and Modern Technology Research Center at Johns Hopkins University, 2021). In the Autonomous Republic of Adjara, as well as throughout the country, the daily number of infections is quite high and the region is second only to the capital in terms of the number of infected. Despite the efforts of the local government and active self-awareness campaigns for citizens, the vaccination of the citizens is still going on at a low pace. All government agencies, local business operators and small businesses are 
involved in the vaccination process. However, according to the available data, the number of vaccinated employees in government institutions is still small. The specific reason for the low activity of employees is the subject of a separate study. However, it should be noted that the Government of the Autonomous Republic of Adjara, as a region with an autonomous status, within the framework of its powers stipulated by the constitutional law, has the opportunity to use additional mechanisms and encourage civil employees in the region to actively participate in the vaccination process.

To stimulate the vaccination process in today's world, the government has developed incentive programs in several countries around the world, the effectiveness of which is reflected in the fact that a large part of the population has already been vaccinated and the country is returning. to a normal life. Vaccination of pre-defined risk groups has become mandatory in a number of European countries, including France and Italy, with compulsory vaccination for military personnel in the United States. In some parts of the Baltic States, teachers are subject to compulsory vaccination, and similar compulsory vaccinations are available in Germany.

In Georgia, as already mentioned, vaccination is voluntary, but it also defines age groups, the process of immunization of which is based on studies and recommendations of the World Health Organization. Currently, there are about 10 centers in the Autonomous Republic of Adjara, where citizens have the opportunity to participate in the vaccination process. Representatives of the local government were among the first to be involved in the vaccination process in the region and called on the population of Adjara to participate as actively as possible in the immunization process. Some employees of budgetary organizations have already been vaccinated in the region, a small part - already in 2 doses. Citizens' activity in relation to the immunization process, including those working in budgetary organizations, remains a problem for the region.

At the initiative of the Government of the Autonomous Republic of Adjara, a vaccination promotion campaign "Get vaccinated" is being launched in the region, the main goal of which is to raise public awareness about the need for vaccination. The campaign is available to locals as well as international or domestic tourists entering the region. Whether these regulations are observed and enforced is a separate issue. (Ministry of Internally Displaced Persons from the Occupied Territories, Labour, Health and Social Affairs of Georgia, 2021). According to the Ministry of Finance and Economy of the Autonomous Republic of Adjara, more than 3,000 people with budget funding work in the region, which is $1.28 \%$ of the total population, which is a fairly high indicator for the region (Ministry of Finance and Economy of Adjara, 2021). Accordingly, local authorities have the 
opportunity to indirectly force public officials to participate in the vaccination process using various forms of incentives.

It is true that the Georgian government has already imposed several new restrictions, including a ban on public transport, entertainment and cultural events, the admission of only vaccinated people in certain facilities, and so on. However, scientists believe that such prohibitions often lead to more aggression among citizens and thus deepen distrust of the immunization process. Therefore, it is necessary to use mechanisms that directly encourage the vaccination process in the region.

\section{Results and Discussion}

The Constitution of Georgia on the Status of the Autonomous Republic of Adjara defines the areas under the special administration, where the region has the opportunity to use specific mechanisms in parallel with the central government, which will be related to sustainable economic, educational, health, agriculture, culture and other spheres (Legislative Herald of Georgia, 2017). In addition, the region has a legislative body - the Supreme Council of Adjara and 4 ministries. Each of them, within their competence, has the opportunity to regulate / define the rules of conduct and authorities of the organizations and employees under their jurisdiction, based on internal laws. Since the sustainable development of the region and the improvement of the socio-economic situation largely depend on the effective work of state institutions and apparatus, it is important for the state to develop mechanisms for maximizing the immunization of employees with vaccines and creating a safe working environment. To achieve this result, the following recommendations can be developed as a result of the present research.

Powerful campaigns to raise awareness of vaccines and immunization. In the first phase of this campaign, a medical portal will be created, which will post the latest information from worldwide research centers on the effects and contraindications of the vaccine. The page will also contain specific examples of people who are highly trusted in society, Access to information should be provided by a specific government agency. In addition, it is important to provide substantiated information regarding various misleading, anti-vaxxers information. This should be based on scientific findings and research findings. In addition to the portal, different types of information sources should be used to make information accessible equally to all age groups. The aforementioned campaign will enable the population of the region to receive timely information on vaccine and immunization issues in a timely manner.

Reducing the working hours of budget-funded employees - In the modern world, in the wake of the Covid pandemic, post-Covid depression and various psychosomatic disorders are increasingly being talked about. Scientists based on studies make recommendations on extending rest. 
Accordingly, within the definition of more free time for budget-funded employees, a special working day regime should be established for vaccinated people, not more than 35 hours per week for a period of 1 year. It is also possible to use various incentives, letters of thanks, certificates and much more. This recommendation, combined with other mechanisms, will allow the region to encourage more people to participate in the immunization process.

Financial incentives for budget-funded employees - In the first phase of the Covid Pandemic in Georgia, a temporary voucher for the unemployed and helpless was provided as part of a government-developed anti-crisis strategic campaign. A similar mechanism can be used to encourage the immunization process. In particular, in order to encourage the process of vaccination for budget financing employees, the employee should be given a salary supplement in the amount of $10 \%$ to $15 \%$. This recommendation, in conjunction with other mechanisms will enable the region to encourage more public officials to be involved in the vaccination process.

Introduction of free health insurance in the public service. One factor contributing to public distrust of the Covid 19 vaccine is the side effects of the vaccine, which have not yet been thoroughly studied. People have questions about their own health in the future. In order to encourage the vaccine of the employee of the budget institution, it is possible to be financed with medical insurance on amount of not less than $5000 \mathrm{GEL}$, which the employee will be able to use in the medical institution of her/his choice for 1 year.

Subsidizing public transport and utility bills - To encourage vaccination by the local municipality, to create a public transport voucher for a public employee, which will allow the passenger to use a $40 \%$ discount on travel for 1 year. Also in case of utility bills with $25 \%$ discount. This incentive mechanism will have a positive impact on citizens and encourage the vaccination process. It is true that in economic terms this percentage needs additional research.

\section{Conclusion}

The present article reviewed the engagement of leading countries of the world in the vaccination process against the Covid-19 and impact of the above-mentioned on the economic growth and uplifting of the restriction within vaccination at the example Georgia. Focus was put on the challenges related to the vaccination process against Covid-19, i.e. low public awareness about vaccination, mistrust or low trust of the population towards vaccination, dissemination of false information about vaccination by anti-vaxxers and low indicator of engagement in the above-mentioned process. With the purpose of introducing new encouragement measures, national and international regulations and literature were reviewed, on the basis of which the challenges existing in Georgian realized were identified. Clear and effective 
communication from the state upon the Covid-10 vaccination and regularly updating the information further strengthened public trust and increased their more active engagement in the vaccination process.

Therefore, transforming the above-mentioned recommendations into practice will greatly support raising public awareness among the population of Georgia in relation to vaccination against Covid-19, and will promote active engagement in the process of vaccination. Taking the above-mentioned encouragement measures and implementation of elaborated recommendations will simplify the process of vaccination for the population, which will result in an increased combating of the Covid-19 pandemic.

\section{References:}

1. Civil.ge. (2021, March 19). Nurse Dies of Presumed Anaphylactic Reaction After Vaccination. https://civil.ge/archives/407145

2. Covid-19 Information Platform of the Ministry of Health of the Republic of Turkey https://covid19asi.saglik.gov.tr/?_Dil=2

3. Constitutional Law of Georgia "On the Status of the Autonomous Republic of Adjara". 010010010.01.001.016013, 13.10.2017, Parliament of Georgia.

4. Deutsches Ärzteblatt International. German Medical Association and the National Association of Statutory Health. (2020, July 15). Was Menschen zu einer Coronaimpfung bewegen könnte.

https://www.aerzteblatt.de/nachrichten/114687/Was-Menschen-zueiner-Coronaimpfung-bewegen-

koennte?fbclid=IwAR3fcgs2yIMzqaObUih9wLe0QH3335nR14yoxp d

https://www.walhalla.de/news/impfpflicht-fuer-beamte\#

5. Georgian National Center for Disease Control and Public Health. 2021. https://www.ncdc.ge/\#/home

6. Government of the AR of Adjara. http://www.adjara.gov.ge/

7. Government of Georgia. Prevention of Coronavirus Spread in Georgia. https://stopcov.ge/

8. Government of Georgia http://gov.ge/

9. Government of Georgia http://gov.ge/

10. Georgia. Parliament of Georgia. 2017. CONSTITUTIONAL LAW OF GEORGIA ON THE STATUS OF THE AUTONOMOUS REPUBLIC OF AJARA. (19/10/2017). Tbilisi: Legislative Herald of Georgia.

https://matsne.gov.ge/en/document/view/30442?publication=2

11. Ministry of Finance and Economy of Adjara.

https://www.mof.ge/en/4393 
12. Ministry of Health and Social Affairs of Adjara AR. 2021. http://adjara.gov.ge/branches/default.aspx?gid=3;

13. Ministry of Internally Displaced Persons from the Occupied Territories, Labour, Health and Social Affairs of Georgia. 2021. https://www.moh.gov.ge/

14. Ministry of Economy and Sustainable Development of Georgia http://www.economy.ge/?page=ecoreview $\& s=44$

15. State Department of Lithuania https://koronastop.lrv.lt/vaccination

16. Science and Modern Technology Research Center at Johns Hopkins University (https://systems.jhu.edu/research/public-health/ncov/

17. The New York Times https://www.nytimes.com/interactive/2020/us/covid-19-vaccinedoses.html

18. World Health Organization. (2021, September 8). Joint COVAX Statement on Supply Forecast for 2021 and early 2022. World Health Organization.

https://www.who.int/news/item/08-09-2021-joint-covax-statementon-supply-forecast-for-2021-and-early-2022 